\title{
A POSSE E A PROPRIEDADE DE BENS IMÓVEIS SOB A ÓTICA DAS CONSTITUIÇÕES E CÓDIGOS CIVIS ARGENTINO E BRASILEIRO
}

\author{
Tamara Luiza Dall Agnol Pinto**
}

\begin{abstract}
RESUMO
$\mathrm{O}$ artigo trata das posses e propriedades perante o direito civil e constitucional argentino e brasileiro. Sabe-se que as correspondentes Constituições desses países têm caráter social preponderante, embora anteriormente o liberalismo tenha influenciado em grande medida as legislações nacionais. Isso implica, não raro, em situações de colisão entre o direito à moradia, por exemplo, e o direito à propriedade privada. Assim, já que essa problemática se faz presente e é causadora de conflitos, importa compreender tais ordenamentos, observando as semelhanças e diferenças entre ambos e suas jurisprudências com o fim de sugerir melhoramentos na aplicação da norma.
\end{abstract}

Palavras-chave: Posse - Propriedade - Direito Comparado - Liberalismo Jurisprudência

\section{POSSESSION AND OWNERSHIP UNDER THE PERSPECTIVE OF THE ARGENTINE AND BRAZILIAN CIVIL CONSTITUTIONS AND CODES}

\begin{abstract}
The article deals with possession and ownership under Argentine and Brazilian constitutional and civil law. The corresponding Constitutions of these countries are known to have a preponderant social character, although previously liberalism has largely influenced national legislations. This often involves collisions between the right to housing, for example, and the right to private property. Thus, since this problem is present and causes conflict, it is important to understand these orders, noting the similarities and differences between both and their jurisprudence in order to suggest improvements in the application of the norm.
\end{abstract}

Keywords: Possession - Ownership - Comparative law - Liberalism - Jurisprudence INTRODUÇÃO

A América Latina abriga países que sofrem regularmente com conflitos por áreas, seja para fins de agropecuária ou outro tipo de atividade econômica, seja para moradia, tanto em zona urbana quanto em zona rural. Nesse contexto, sabe-se da existência de vários grupos

\footnotetext{
* Advogada inscrita na OAB/MA, especialista em Direito Civil pela UNIDERP (MS), pós-graduanda em Escola Austríaca de Economia pelo Instituto Mises Brasil em parceria com a Ítalo Brasileiro - SP, mestranda em Direito pela Universidade Federal do Maranhão (UFMA) - área de concentração: Direito Privado Contemporâneo e sua aplicação pelas Instituições do Sistema de Justiça, aluna regular do programa de Doutorado em Direito Civil da UBA (Universidad de Buenos Aires - Argentina). Correio eletrônico: tamara_dall@hotmail.com
} 
organizados que reivindicam espaços a quem, em teoria, não possui posses ou propriedades. Como exemplo, pode-se citar os Movimento Okupa na Argentina e o MST (Movimento Sem Terra) no Brasil.

Não raras vezes o que se depreende nos casos em concreto é uma situação de estigmatização advinda de ambas as partes envolvidas no conflito em relação a outra, sem, contudo, haver sinais, nestes países, de que o cenário hostil tende a cessar. Logicamente são realidades diferentes as vivenciadas nesses países, embora os enfrentamentos tenham origem muito semelhante, típica da situação de baixo desenvolvimento humano que assola o continente.

Os esforços advindos do Poder Público para extinguir situações de risco à propriedade privada e posses justas/de boa-fé, assim como o uso de violência nesse contexto, não conseguem reduzir significativamente suas ocorrências.

No que toca à legislação pertinente, tanto Argentina quanto Brasil apresentam um Direito Civil bastante alinhado, inclusive porque o esboço feito ao Brasil por Teixeira de Freitas exerceu grande influência na feitura do Código Civil argentino (DINIZ, 2011, p. 64), que surgiu em 1871, advindo apenas em 1916 o brasileiro, depois de muitos debates e revisões.

Mais recentemente, em 2016, na Argentina, entrou em vigor o "Código Civil y Comercial de La Nación", enquanto no Brasil, desde 2002, conta-se com um Código Civil atualizado, claramente, mas que ainda conta com muitas repetições do anterior, inclusive na parte atinente aos Direitos Reais, que constam na parte especial da codificação (livro III), tal qual o livro quatro abriga essa mesma temática no Código argentino.

Assim, analisar-se-ão as diferenças e semelhanças entre os dois Códigos no que se refere à propriedade e à posse de bens imóveis por sua natureza, bem como entre as duas Constituições, sempre levando em consideração a realidade conflitiva desses países no que toca à propriedade imóvel e também as razões filosóficas e econômicas do seu status quo, já que se trata de uma problemática que muito envolve a ingerência pública e, por consequência, a política.

Metodologicamente, importa destacar, a pesquisa é exploratória, bibliográfica e é trazida possível contribuição do liberalismo para a diminuição conflitiva, bem como a 
jurisprudência dos países em alusão relativa aos subtemas selecionados, como convalidação de posse injusta e a aplicação da função social da propriedade.

\section{Panorama geral da propriedade privada}

Um dos sentimentos mais marcantes dos seres humanos em relação às coisas é o de possuí-las. Desde muito jovens aprendemos os pronomes possessivos: "meu", "teu", dentre outros, o que muito provavelmente revela uma característica inata de todos os indivíduos. $\mathrm{O}$ direito, como premissa de organização em sociedade, tendo em vista a forte influência da cultura ocidental e a existência de institutos jurídicos privados, originários, em grande medida, do direito romano, acolheu determinadas concepções e as desenvolveu/adaptou.

Nesse ínterim, o direito real, diferentemente do direito pessoal,

consiste no poder jurídico, direto e imediato, do titular sobre a coisa, com exclusividade e contra todos. No polo passivo incluem-se os membros da coletividade, pois todos devem abster-se de qualquer atitude que possa turbar o direito do titular. No instante em que alguém viola esse dever, o sujeito passivo, que era indeterminado, torna-se determinado.

Logo, o objeto dos Direitos Reais, "es generalmente la cosa, que debe ser certa, actual y determinada" (KIPER, 2016, p. 29), oponível a terceiros (erga omnes). O art. 1.225 do Código brasileiro, em rol taxativo (numerus clausus), elenca quais são os direitos reais. Dentre eles, está a propriedade privada (inciso I), considerado o direito real por excelência, assim como Kiper (2016, p. 136) coloca que "el domínio como derecho real es el mayor sometimiento de que puede ser objeto una cosa a una persona".

A propriedade privada goza de proteção pela Constituição Federal brasileira, art. $5^{\circ}$, inc. XXII e 170, inc. II. Enquanto no âmbito argentino, protege-se a propriedade por meio dos artigos 14 e 17 da sua correspondente Constituição. Nota-se, entretanto, que a legislação argentina dá conceituação distinta à "propiedad" posta na Suprema Carta e "domínio", presente no novo Código Civil e Comercial, que corresponderia à terminologia "propriedade" na codificação brasileira. Na verdade, se trata apenas de uma mudança de terminologia, não obstante o Código brasileiro semanticamente dá à "propriedade" o domínio pleno da coisa, móvel ou imóvel. Cumpre esclarecer que nesta oportunidade tratar-se-á apenas da propriedade e posse de bem imóvel. 
Bens imóveis são "aqueles que não se podem transportar, sem destruição, de um lugar para o outro" (BEVILAQUA, p. 267 apud DINIZ, 2011, p. 362). Ademais, ao classificálos, o Código Civil (arts. 79 e 80) pontua os imóveis por sua natureza, por acessão física artificial, por acessão intelectual e por determinação legal. Ocupar-se-á aqui dos imóveis por sua natureza.

No que tange à definição de propriedade privada, o art. 1.228 a conceitua como a faculdade de usar, gozar e dispor da coisa, e o direito de reavê-la do poder de quem quer que injustamente a possua ou detenha. Por outro lado, o art. 1.941 do Código argentino assim concebe o domínio: "es el derecho real que otorga todas las facultades de usar, gozar y disponer material y jurídicamente de una cosa, dentro de los límites previstos por la ley”.

De outro lado, está a posse, também relevante neste estudo, já que, embora não seja direito real, é elemento constitutivo da propriedade, visto que, em regra, o proprietário está na posse do seu bem, e, quando não, geralmente significa que, por sua faculdade, a título oneroso ou não, concedeu a outrem a posse da coisa.

Na Argentina, devido ao artigo 1.909, para explicação da posse, "se aprecia la adhesión a la teoría subjetiva de Savigny, con alguna atenuación ya que pone el acento en el comportamiento, en lugar de la intención” (KIPER, 2016, p. 55), embora o corpus e o animus domini estejam presentes.

No Brasil, a doutrina diverge entre a adoção da teoria híbrida (que abriga teoria subjetiva e objetiva), a adoção da teoria de Ihering (objetiva), ou ainda, a teoria da possesocial, defendida por Tartuce (2014, p. 41), para quem:

\footnotetext{
tendo a propriedade uma função social reconhecida no Texto Maior, o mesmo deve ser tido quanto à posse. Diante desses argumentos, entendemos ser mais correto afirmar, atualmente, que o Código Civil não adota a tese de IHERING, pura e simplesmente, mas sim a tese da posse-social, como defendem PEROZZI, SALEILLES e GIL [...] razão pela qual o debate entre IHERING e SAVIGNY encontra-se mais do que superado.
}

Entretanto, embora seja a propriedade protegida em nossos ordenamentos, por razões que melhor serão trabalhadas nos próximos tópicos, não é tida como um direito absoluto, hajam vistas as inúmeras possibilidades de restrição as quais são passíveis em prol do bem comum. Além do contexto histórico e político que transformou o direito em alusão, 
tão caro à liberdade individual, muito em voga está a tendência de constitucionalização do direito civil.

Seria esse fenômeno a interpretação de regras contidas no ordenamento conforme à Constituição, além da inclusão à Carta Magna de matérias comumente legisladas infraconstitucionalmente. Tudo isso para que seja atendida a finalidade última da Constituição, bem como para garantir a aplicação dos seus princípios. Essa propensão também é verificada na Argentina, como confirma Abreu, destacando a valorização dos direitos de incidência coletiva:

el nuevo código ha recepcionado compromisos internacionales asumidos en los tratados de derechos humanos con jerarquía constitucional, en favor de la protección de las comunidades originarias, así como los derechos de incidencia colectiva como el derecho a um ambiente sano y equilibrado (ABREU, 2017, p. 148)

Também nesse sentido conclui Kiper (2016, p. 135), ao tratar de propriedade e da filosofia do novo código: "además de mantener la teoría del abuso del derecho, hace alusión a los tratados de derechos humanos, resguarda los derechos de incidência colectiva incluso limitando derechos".

Nessa senda, questiona-se aqui se realmente essa contemporânea concepção do direito à propriedade, fortemente firmada pela legislação e pela doutrina, realmente traduz efeitos positivos à sociedade, ou se não geraria demasiado estímulo ao desrespeito de um direito que envolve alto grau de consenso social. A necessidade de observância da função social da propriedade, assim como várias outras restrições ao exercício desse direito, permissivas da agressão à liberdade individual, claramente é um desdobramento nítido de toda a filosofia aflorada no pós-guerra e maximizada pelas ideias que foram fortemente pregadas nos países latino americanos nos últimos 30 anos.

Com o fim de verificar o que significa, na prática, as determinadas escolhas estatais que compõem atualmente a norma jurídica argentina e brasileira com respeito ao tema, passar-se-á a tratar especificamente, mas não exaustivamente, da possibilidade de convalidação da posse e da função social da propriedade.

\section{A convalidação da posse injusta e a função social da propriedade}


Um grande exemplo de que o Código Civil brasileiro não inovou tanto assim na sua versão de 2002 é justamente o art. 1208, que coloca: "não induzem posse os atos de mera permissão ou tolerância assim como não autorizam a sua aquisição os atos violentos, ou clandestinos, senão depois de cessar a violência ou a clandestinidade", praticamente idêntico ao art. 497 do anterior Código de 1916.

Em face deste artigo, o vício da violência e o da clandestinidade são temporários, quando por direito romano prevalecia a regra: quod ab initio vitiosum est non potest tractu temporis convalescere. Pelo Código Civil, desde que a violência e a clandestinidade cessam, a posse começa a firmar-se utilmente, de modo que, passados anos, não seja o possuidor despojado dela, simplesmente por esse vício originário. (BEVILAQUA, 1958, p. 19)

Nosso direito positivado classifica a posse em justa e injusta. Sendo a injusta decorrente de três diferentes e alternativas situações, quais sejam: violência, clandestinidade ou precariedade. Tal qual ocorre na Argentina, observado o art. 1.921 do novo Código.

Entretanto, no dispositivo argentino, não existe a expressão "senão depois de cessar a violência ou a clandestinidade". Ou seja, nesse país, acertadamente, uma posse injusta, ou viciosa, como queiram, manterá esse caráter perpetuamente.

Na realidade brasileira, contudo, referida expressão dá brecha para entender que a posse injusta lograda via clandestina ou com uso da violência, pode convalidar-se, ou seja, tornar-se justa. Mas parece razoável que, nessa situação, a posse venha a tornar-se justa, inclusive havendo a possibilidade de futuramente requerer o possuidor a usucapião?

A doutrina diverge. Quintella (2016), questiona o mesmo, porém enfatizando a diferença que o Código faz em relação à posse adquirida via abuso de confiança (precária), a qual não se convalidaria jamais. Curiosamente a legislação brasileira trata a posse precária de modo distinto da clandestina e da violenta, quando é nítida a maior gravidade do modo de aquisição relativo às duas últimas.

Tartuce, assim como Quintella, faz essa ponderação, embora sua conclusão seja mais radical, visto que para ele a posse precária também não deveria ser impedida de convalidação.

Para o civilista brasileiro (p. 45-46),

o dispositivo acaba quebrando a regra pela qual a posse mantém o mesmo caráter com que foi adquirida, conforme o art. 1.203 do $\mathrm{CC} / 2002$, e que consagra o princípio da continuidade do caráter da posse. Ato contínuo, reconhece que aqueles 
que têm posse violenta ou clandestina não tem posse plena, para fins jurídicos, sendo meros detentores. Tal previsão causa perplexidade, pois acaba negando o conceito de posse injusta, entrando em clara contradição com o art. 1.200 da própria codificação.

Ademais, como pode a Constituição elencar a propriedade privada como direito fundamental e permitir, em divergência, que um invasor que adentrou a propriedade alheia com violência se torne o proprietário do imóvel via usucapião após algum tempo?

Diante de várias contradições legais, fica a cargo dos operadores do direito a atividade hermenêutica necessária. A posição mais acertada, sob o nosso ponto de vista é a do Desembargador do Tribunal de Justiça do Estado de São Paulo, Francisco Eduardo Loureiro, quando tece seus comentários ao artigo 1.208 do Código Civil Comentado (editora Manole ed. 2007, p. 1.008):

Via de conseqüência, nos exatos termos da segunda parte deste artigo, enquanto perduram a violência e a clandestinidade, não há posse, mas simples detenção. No momento em que cessam os mencionados ilícitos, nasce a posse, mas injusta, porque contaminada de moléstia congênita. Dizendo de outro modo, a posse injusta, violenta ou clandestina, tem vícios ligados à sua causa ilícita. São vícios pretéritos, mas que maculam a posse mantendo o estigma da origem. Isso porque, como acima dito, enquanto persistirem os atos violentos e clandestinos, nem posse haverá, mas mera detenção.

De outro lado, a legislação argentina não permite essa discussão, porquanto a convalidação da posse viciosa não tem previsão legal, o que favorece a existência de uma segurança jurídica maior ao proprietário ou possuidor de boa-fé, como se depreende das seguintes determinações:

ARTICULO 1916 - Presunción de legitimidad. Las relaciones de poder se presumen legítimas, a menos que exista prueba en contrario. Son ilegítimas cuando no importan el ejercicio de un derecho real o personal constituido de conformidad con las previsiones de la ley.

ARTICULO 1921 - Posesión viciosa. La posesión de mala fe es viciosa cuando es de cosas muebles adquiridas por hurto, estafa, o abuso de confianza; y cuando es de inmuebles, adquiridos por violencia, clandestinidad, o abuso de confianza. Los vicios de la posesión son relativos respecto de aquel contra quien se ejercen. En todos los casos, sea por el mismo que causa el vicio o por sus agentes, sea contra el poseedor o sus representantes.

Assim,

puede decirse que la posesión es viciosa cuando es adquirida ilegalmente, sin o contra la voluntad del poseedor, es decir, mediante despoderamiento. Se da sin la conformidad del poseedor cuando hay clandestinidade, y contra su voluntad cuando hay violência o abuso de confianza. En general, la posesión viciosa dimana de una 
apropiación o desapoderamiento prohibidos por la ley civil y reprimidos por la ley penal (KIPER, p. 80, 2016).

Conclui-se que a lei civil argentina, além de não prever a situação de convalidação na hipótese apreciada, ainda conta com uma doutrina que condena as práticas atinentes à posse viciosa, haja vista configurarem-se ilícitos civil ou/e penal.

Em relação à função social da propriedade, por sua vez, sua presença nas Constituições do século passado afloraram as discussões quanto ao seu alcance e influência na proteção da propriedade. Tal cláusula geral fica a cargo do subjetivismo do intérprete, de modo que atualmente alguns autores, em decorrência disso, afirmem que

a única diferença concreta entre a posse e a propriedade, para o direito positivo atual, é que a propriedade é legitimada pelo estado, enquanto que a posse não precisa de chancela estatal para ser exercida, sendo uma situação vista no caso concreto (SANTORO, 2011).

É certo que a função social revolucionou de tal ordem o referido instituto, de maneira que atualmente, em determinadas situações, é mais benéfico ser possuidor do que ser proprietário. Exemplifica-se com o caso de um grande grupo de ativistas que invade um terreno particular cujo dono anseia vender e, como o dono não dá destinação social ao imóvel naquele momento, e pelo risco de represália, teme utilizar-se da autotutela para defender-se do esbulho. Consequência: um ano e um dia depois, a posse é justa e, residindo lá os invasores, muito dificilmente o proprietário terá o domínio da área novamente.

Já a Argentina também possui a função social em sua Constituição (não expressamente), visto que, assim como o Brasil, é signatária do Pacto de São José da Costa Rica - Convenção Americana de Direitos Humana (1969), que assim estabelece:

Artigo 21 - Direito à propriedade privada

1. Toda pessoa tem direito ao uso e gozo de seus bens. A lei pode subordinar esse uso e gozo ao interesse social.

2. Nenhuma pessoa pode ser privada de seus bens, salvo mediante o pagamento de indenização justa, por motivo de utilidade pública ou de interesse social e nos casos e na forma estabelecidos pela lei.

No Código Civil e do Comércio da Nação Argentina, contudo, embora seja recente sua redação (2016), não há qualquer menção a esse instituto, como acontece no 
Código Civil brasileiro, que ademais da função social da propriedade, também destaca em vários momentos a função social dos contratos, limitando indubitavelmente a liberdade e autonomia contratual.

Ao contrário, o Código argentino realça o caráter de perpetuidade da propriedade, como se percebe no seguinte artigo: "1942 - Perpetuidad. El dominio es perpetuo. No tiene límite en el tiempo y subsiste con independencia de su ejercicio. No se extingue aunque el dueño no ejerza sus facultades, o las ejerza otro, excepto que éste adquiera el dominio por prescripción adquisitiva". Além de trazer também que a propriedade - "el domínio" - é exclusiva. Enquanto isso, a codificação brasileira silencia quanto a essas características, constando apenas na doutrina.

Portanto, o que se conclui é que o Código Civil e Comercial não incorporou as noções sociais presentes na Constituição em seu regramento, inclusive porque, em dissenso com a literalidade do Código anterior, não manteve o exercício regular do direito como um limite ao exercício da propriedade, como claramente especificava o Código anterior.

Atualmente, na codificação argentina, a única disposição a respeito de restrições de direitos se encontra nas disposições gerais do Código, capítulo 3, em virtude do artigo 10 ordenar:

\footnotetext{
ARTICULO 10 - Abuso del derecho. El ejercicio regular de un derecho propio o el cumplimiento de una obligación legal no puede constituir como ilícito ningún acto. La ley no ampara el ejercicio abusivo de los derechos. Se considera tal el que contraría los fines del ordenamiento jurídico o el que excede los límites impuestos por la buena fe, la moral y las buenas costumbres. El juez debe ordenar lo necesario para evitar los efectos del ejercicio abusivo o de la situación jurídica abusiva y, si correspondiere, procurar la reposición al estado de hecho anterior y fijar una indemnización.
}

Na sequência, uma vez superadas algumas semelhanças e diferenças entre as ordenações argentina e brasileira, vislumbrar-se-á a problemática sob o marco do liberalismo, e como sua prática poderia contribuir para evitar situações conflitivas envolvendo posse e propriedade.

\section{As contribuições do liberalismo para a temática}

As Constituições pós-guerra foram outorgadas levando a cabo grandes influências do Welfare State, ou Estado de Bem-Estar Social. Deixou-se de lado o liberalismo clássico que valorizava o individualismo, e, em grande parte devido às atrocidades ocorridas no século 
passado, a dignidade da pessoa passou a ter relevante espaço, bem como os direitos sociais. De um estado negativo, no sentido de não-agressão da liberdade, de abstenção, passou-se a um estado intervencionista, paternalista, regulador. Achava-se, assim, que a segurança da sociedade estaria mais garantida.

Nesse contexto, as Constituições contemporâneas mantiveram em seus bojos a proteção à propriedade privada (em sentido amplo), porém, de outro lado, como foi visto, são inúmeras as restrições que sofre esse direito.

\begin{abstract}
Enfocando a ideia comum a todas as definições, função social da propriedade é o instituto que legaliza a intervenção do governo na propriedade privada, sob o argumento de um interesse público relevante, suprimindo ou extinguindo o poder do indivíduo sobre o bem anteriormente plenamente privado. Portanto, a base filosófica dessa intervenção é o interesse público. Interesse público, segundo a doutrina administrativista clássica, é a consecução do bem comum. O governo pode, então, suprimir ou extinguir a propriedade privada das pessoas tendo em vista o bem comum, e a ideia de bem comum muda de acordo com a filosofia política e econômica de um governo. Alguns governos podem achar que uma dada propriedade visa o bem comum apenas se atingir uma certa quantidade de produção de arroz, ou se aquele imóvel for destinado para o comércio, e não para a moradia (SANTORO, 2011).
\end{abstract}

Destaca-se, pois, a carga subjetiva que pode ser destinada a "bem comum", o que pode gerar tamanha insegurança jurídica. Isso vai ficar ainda mais evidente no próximo tópico, onde depreender-se-ão os inúmeros significados dados à função social em cada caso em concreto.

O referido autor segue defendendo a teoria de que, na prática, a propriedade privada no Brasil não existiria e, na verdade, o que se tem são detentores que exercem a relação de poder para com a coisa em nome do Estado e baixo aos seus ditames, o que faz muito sentido, visto que as restrições ao direito retiram, em grande medida, o exercício de gozo, uso e fruição.

No que concerne à posição liberal, o único modo de transferência de propriedade é a voluntária, não podendo haver nenhuma forma de agressão à propriedade do outro, sob pena de sanção e indenização.

Em particular, uma vez que um bem ou um local foi apropriado originalmente por uma pessoa que - nas palavras de John Locke - "misturou seu trabalho" a esse bem ou local, então a propriedade desse bem ou local somente poderá ser legada a terceiros através de uma transferência voluntária - contratual - de um título de propriedade. (HOPPE, 2010) 
Nota-se que Hoppe menciona "apropriado originalmente", o que significa que aquela coisa apropriada antes não tinha um titular. O que é totalmente diferente das situações conflitivas levadas a cabo nos países em apreço, em que não raras vezes o uso da violência acontece, privando o outro da sua liberdade. Como Rothbard (2010, p. 104), descreve:

\begin{abstract}
Há, no entanto, outro tipo muito diferente de relação interpessoal: o uso da violência agressiva de um homem contra outro. Esta violência agressiva significa que um homem invade a propriedade de outro sem o consentimento da vítima. A invasão pode ser contra a propriedade de um homem de sua própria pessoa (como no caso de um ataque físico), ou contra sua propriedade de bens tangíveis (como no caso de roubo ou de invasão). Em qualquer um dos casos, o agressor impõe sua vontade sobre a propriedade natural de outro homem - ele priva o outro homem de sua liberdade de ação e do exercício total de sua autopropriedade natural.
\end{abstract}

O que se tem pregado nos últimos 30 anos, especialmente, é que o bem-estar social adviria de garantias sociais, de um intervencionismo exacerbado, e que a propriedade privada se prestaria a aumentar a disparidade socioeconômica populacional.

Entretanto, caso a propriedade fosse respeitada - não integralmente, mas ao menos quase integralmente - o índice de desenvolvimento humano aumentaria, embora continuasse havendo desigualdade, que é normal, visto que numa sociedade há indivíduos mais criativos, mais empreendedores, mais esforçados que outros. É o que Mises (2018, p. 37) destaca quando cita aqueles que "têm o dom de descobrir novos caminhos, de mudar os rumos do conhecimento. Nas sociedades capitalistas, o progresso tecnológico e econômico é promovido por esses homens", afirma ele.

\footnotetext{
A ideia da propriedade privada, além de estar de acordo com a nossa intuição moral e ser a única solução justa para o problema da ordem social, representa algo ainda maior: a instituição da propriedade privada é também a base da prosperidade econômica e do "bem-estar social". Se as pessoas agirem de acordo com as regras que fundamentam a instituição da propriedade privada, o bem-estar social será otimizado (HOPPE, 2011).
}

É concebida, pois, a não-agressão, a liberdade de maneira negativa, advinda de um não fazer do outro, desde que um indivíduo também não agrida a liberdade do seu semelhante. Trabalha-se a ideia da abstenção, portanto, e de cooperação mútua, já que um indivíduo, embora anseie uma omissão do outro em relação às suas liberdades, precisa dos demais no que toca às suas necessidades numa economia complexa. Rothbard (2010, p. 93) 
justifica esse contexto nas leis naturais que norteiam a teoria econômica: (a) a grande variedade de habilidades e de interesses peculiares a cada pessoa; e (b) a variedade de recursos naturais nas diferentes áreas geográficas.

Finalmente, toda troca (transferência) voluntária de propriedade - seja ela uma
propriedade adquirida ou produzida - entre duas pessoas, também aumenta o bem-
estar social. Uma troca de propriedade só é possível se ambos os proprietários
preferem aquilo que irão obter àquilo de que estão abrindo mão. E com isso ambos
esperam se beneficiar da troca. Duas pessoas melhoram seu bem-estar após cada
troca de propriedade, enquanto que a propriedade sob o controle de todas as outras
pessoas permanece inalterada. Em um contraste marcante, qualquer desvio da
instituição da propriedade privada necessariamente levará a perdas no bem-estar
social (HOPPE, 2011).

Esse panorama se cruza à temática proposta, visto que no tópico anterior ficou registrada a possibilidade de convalidação pela codificação civil brasileira, além da marcante presença da função social, ambos meios de estimular a agressão da propriedade alheia. Porquanto a primeira apenas impossibilite a conversão de posse injusta em justa na situação de abuso de confiança como forma de obtenção, e a segunda é frequentemente utilizada como argumento para o esbulho, em situações que não se depreende abandono por parte do proprietário, mas sim o fato de "não residir", "não produzir", "especular", dentre outras situações que em nada ferem liberdades alheias.

Assim, embora possa parecer que o Brasil está mais avançado em termos de legislação que a Argentina, é necessário averiguar a realidade dos dois países no que concerne à existência dos conflitos que envolvem disputas por propriedades privadas imóveis. Nem sempre o que é "atual" é melhor do que havia anteriormente.

Destarte, é possível que a legislação brasileira, considerada "avançada", esteja fazendo o caminho inverso do desejado. Ou seja, estimulando invasões, a existência de posses injustas, o esbulho, ao invés de viabilizar a autorresponsabilidade e a aquisição de propriedades pelos meios de livre mercado.

Essa visão liberal não se opõe à finalidade última dos indivíduos enquanto pertencentes de uma sociedade no que toca às propriedades, visto que fornece segurança às relações. Ademais, como Mises (2018, p. 34) propaga, o capitalismo e a propriedade possibilitam que haja uma constante mobilidade social, o que não acontecia até certo momento da história, a exemplo da sociedade de status. Portanto, supracitada segurança vai também alcançar o agressor quando este estiver no papel de proprietário, inclusive porque na sociedade atual a mobilidade é comum e frequente. 
Por esta razão, corroboramos uma definição mais adequada de propriedade, já proposta por Santoro (2011):

\begin{abstract}
é o exercício de fato, por um indivíduo, da faculdade de usar, gozar (fruir) e dispor de um bem escasso, independentemente da chancela estatal, exercido de maneira original sobre bens escassos sem dono ou através de acordo voluntário com quem originalmente o exerceu ou os sucessores deste, além do direito de reavê-lo de quem injustamente o possua ou detenha.
\end{abstract}

Assim, tendo em vista a existência de conflitos causados pelas disputas envolvendo a propriedade, seria o conceito liberal, diferentemente do que se acredita majoritariamente hoje, uma maneira de, ao respeitar a propriedade, reconhecendo-a como direito absoluto, promover a cooperação dos indivíduos na divisão social do trabalho realizada pelo mercado, num cenário em as pessoas estão contribuindo para o funcionamento global da sociedade (MISES, 2018, p. 27).

No que se refere à argumentação favorável à função social da propriedade de que sua inobservância possibilitaria a agressão ao direito de propriedade do outro, é necessário vislumbrar o posicionamento de Braga (apud SANTORO, 2011), condizente ao entendimento da propriedade como direito absoluto. Afirmando que "é justamente o caráter absoluto dessa propriedade que justifica a reparação à propriedade do cidadão prejudicado, não havendo, no caso, nenhuma relativização no conceito de propriedade".

Logo, para ilustrar e compreender melhor como, na prática, as legislações estão sendo interpretadas e aplicadas, o próximo tópico se dedica a analisar algumas jurisprudências argentinas e brasileiras sobre o tema.

\title{
4 Comparações jurisprudenciais
}

O Brasil, embora tenha extensão territorial continental, é palco de muitos conflitos por terras, e muito provavelmente essas situações podem estar sendo estimuladas pela legislação demasiadamente flexível do ponto de vista social, o que permite muito facilmente a agressão ao direito fundamental à propriedade.

Segundo dados do relatório "Defender la Tierra - Asesinados globales defensores/as de la tierra y el medio ambiente en 2016", produzido pela Global Witness, o Brasil lidera o ranking de assassinatos, com 49, seguido por Colômbia, 37 mortes, Filipinas, 
28, Índia, 16, Honduras, 14, Nicarágua, 11, República Democrática do Congo, 10, Bangladesh, 7, Guatemala, 6, e Irã, 3.

Tais dados demonstram que a Argentina, ainda que também sofra com conflitos do gênero, está muito atrás nesse ranking em comparação com o Brasil, ao menos no quesito mortes decorrentes de tais conflitos, visto que sequer consta no relatório. O movimento Okupa, muito conhecido na Argentina, embora não se limite a esse país, com certa regularidade promove invasões de imóveis, agredindo o direito alheio. Entretanto, não é tão ativo quanto o MST no Brasil, por exemplo, nem exerce o mesmo grau de influência no poder público. Em que pese, logicamente, ambos grupos de pressão cumprirem suas pautas de conotação política e, às vezes, partidária.

Na sequência, passa-se a enumerar jurisprudências brasileiras (dos últimos dois anos) e argentinas, nessa ordem, condizentes à temática. A primeira e recente decisão advém do estado de São Paulo e trata de invasão, assim denominada pelo próprio magistrado de $2^{\circ}$ grau, que não obteve êxito quando do pleito pela usucapião devido configurar posse injusta por clandestinidade, ficando claro o posicionamento do juízo desfavorável à convalidação:

Reintegração na posse de imóvel urbano - Posse antecedente, legítima, proveniente de instrumento de venda e compra do terreno devidamente quitado - Esbulho caracterizado pelo ingresso clandestino e arbitrário no imóvel - Ocupação injusta, desmunida de boa-fé, sem a viabilidade de convalidação perante o direito positivo, diante da ciência inequívoca do vício primitivo contemporâneo à invasão Incidência dos arts. 1.200, 1.203 e 1.208 do Código Civil - Posse precária e clandestina, impeditiva da usucapião - Inexistência de prova cabal de abandono, renúncia ou outro modo da perda da posse - Sentença mantida - Recurso não provido. (TJ-SP 10015881120168260472 SP 1001588-11.2016.8.26.0472, Relator: César Peixoto, Data de Julgamento: 01/08/2018, $38^{\mathrm{a}}$ Câmara de Direito Privado, Data de Publicação: 01/08/2018)

A seguir, a "melhor posse" é condicionada ao cumprimento da função social:

APELAÇÃO CÍVEL. DIREITO CIVIL. POSSE. REINTEGRAÇÃO. ESBULHO. REQUISITOS DA AÇÃO POSSESSÓRIA. IMÓVEL NÃO REGULARIZADO. MELHOR POSSE. FUNÇÃO SOCIAL DA PROPRIEDADE. 1. O possuidor tem direito a ser reintegrado em caso de esbulho, basta provar a sua posse, o esbulho, a data do esbulho e a perda da posse. 2. Considera-se possuidor todo aquele que tem de fato o exercício, pleno ou não, de algum dos poderes inerentes à propriedade: de usar, gozar e dispor da coisa. 3. "Tratando-se (...) de imóvel situado em área não regularizada, a proteção possessória deve ser concedida àquele que possui a 'melhor posse', evidenciada, inclusive, a partir do implemento da função social da propriedade." (Acórdão n.1072387, 20170310158413APC, Relator: Romulo de Araujo Mendes, $1^{\mathrm{a}}$ Turma Cível, Data de Julgamento: 31/01/2018. Publicado no DJE: 07/02/2018. Pág.: 488-503). 4. Apelação desprovida. (TJ-DF 20170510016642 DF 0001646-68.2017.8.07.0005, Relator: HECTOR VALVERDE, Data de 
Julgamento: 29/08/2018, $1^{\text {a }}$ TURMA CÍVEL, Data de Publicação: Publicado no DJE :31/08/2018. Pág.: 257-259

No próximo caso, embora trate de bens móveis, curiosamente o relator do estado do Rio Grande do Sul autoriza a usucapião por precarista, hipótese em que o próprio Código Civil não inclui a posse precária dentre as possibilidades de convalidação. O intérprete utilizase da fundamentação da função social da propriedade para fundamentar sua decisão:

\begin{abstract}
APELAÇÃO CÍVEL. USUCAPIÃO. BENS MÓVEIS. INTERVENÇÃO DA POSSE PRECÁRIA. FUNÇÃO SOCIAL DA PROPRIEDADE E DA POSSE. Se o direito de propriedade se legitima (e então cumpre sua função social) pela utilização econômica, aquele que, sendo privado da posse por precarista, se mantém inerte pelo tempo necessário para consumar a aquisição, perde seu direito de propriedade, e consequentemente, deve sucumbir ante a uma ação de usucapião, possessória ou reivindicatória. APELO PROVIDO. (Apelação Cível No 70076274927, Décima Quarta Câmara Cível, Tribunal de Justiça do RS, Relator: Roberto Sbravati, Julgado em 29/03/2018). (TJ-RS - AC: 70076274927 RS, Relator: Roberto Sbravati, Data de Julgamento: 29/03/2018, Décima Quarta Câmara Cível, Data de Publicação: Diário da Justiça do dia 04/04/2018)
\end{abstract}

Por conseguinte, no próximo julgado, o relator do TRF-3, em caso ocorrido em São Paulo, acertadamente chama a atenção na sua fundamentação para a correta aplicação da função social da propriedade, discorrendo que ela não deve ser pretexto para a manutenção dos assentados na área. Ainda ressalta a importância do INCRA em obedecer ao programa, sob pena de fomentar invasões:

PROCESSUAL CIVIL. REINTEGRAÇÃO DE POSSE. ASSENTAMENTO DO INCRA. OCUPAÇÃO IRREGULAR. FUNÇÃO SOCIAL DA PROPRIEDADE. APELO DESPROVIDO. I - A teor do conjunto probatório trazido aos autos pela parte autora, não existe documento hábil à comprovação do fato constitutivo do seu direito, nos termos do artigo 373, inciso I, do Novo Código de Processo Civil, motivo pelo qual denota-se que os autores não se desincumbiram do ônus que lhe cabia. II - Cabe à autarquia realizar o assentamento nos termos do seu planejamento, respeitando os aspectos ambientais e o programa elaborado, sob pena de fomentar a invasão de terras, não havendo que se falar em manutenção dos apelantes na posse sob o pretexto de realização da função social da propriedade. III - A ocupação irregular do lote em questão justifica a reintegração, cabendo ao INCRA realizar o assentamento de acordo com o programa elaborado. IV - Apelação desprovida. (TRF-3 - AC: 00098574820094036107 SP, Relator: DESEMBARGADOR FEDERAL COTRIM GUIMARÃES, Data de Julgamento: 10/10/2017, SEGUNDA TURMA, Data de Publicação: e-DJF3 Judicial 1 DATA:19/10/2017)

Também do Distrito Federal vem outro julgado em que se fez prevalecer a propriedade privada em face até mesmo da sua função social, o que não é comum:

Reintegração de posse. Esbulho. Prova. Função social da propriedade. Contestação. Matéria de defesa. Preclusão. 1 - Na ação de reintegração de posse, incumbe ao 
autor provar a sua posse, o esbulho praticado pelo réu, a data do esbulho e a perda da posse (CPC/15, art. 561). 2 - O fato de o imóvel encontrar-se desocupado não autoriza que seja invadido, invasão que, caracterizando esbulho, autoriza a proteção por meio dos interditos possessórios. 3 - A função social da propriedade não se sobrepõe à proteção que a Constituição confere a propriedade privada. 4 - O momento processual adequado para o réu alegar existência de fato impeditivo, modificativo ou extintivo do direito do autor é na primeira oportunidade, ou seja, na contestação. 5 - Apelação não provida. (TJ-DF 201213100431850004055 54.2012.8.07.0017, Relator: JAIR SOARES, Data de Julgamento: 25/01/2017, $6^{\text {a }}$ TURMA CÍVEL, Data de Publicação: Publicado no DJE: 31/01/2017. Pág.: 720/732).

De modo diametralmente oposto, a decisão gaúcha da sequência, por sua vez, considerou descumprimento da função social o ato do vizinho que se nega a podar a árvore do seu terreno que chega ao lindeiro. A interpretação revelaria, então, a necessidade de desapropriação por ato que sim, agride o direito do vizinho, mas num potencial ofensivo mínimo?

\begin{abstract}
RECURSO INOMINADO. DIREITO DE VIZINHANÇA. ÁRVORES QUE DESCAEM SOBRE TERRENO LINDEIRO, SUJANDO PISCINA. USO NOCIVO DA PROPRIEDADE. ABUSO DE DIREITO. FUNÇÃO SOCIAL DA PROPRIEDADE. BOA-FÉ OBJETIVA. 1. Age em abuso de direito, em ofensa à cláusula-geral da boa-fé objetiva e em infringência ao princípio da função social da propriedade vizinho que, modo infundado, não coopera e se nega a podar árvores plantadas em seu terreno, lindeiro ao da contraparte, permitindo que galhos e folhas descaiam sobre a piscina construída pelo vizinho, causando-lhe danos. 2. Embora o vizinho prejudicado seja titular de direito potestativo de cortar as árvores no que sobeje a linha divisória entre os lotes, não lhe é exigível tal faina e as despesas decorrentes, cumprindo ao proprietário cooperar e realizar a poda. 3. Não havendo prova de que os produtos utilizados para manutenção da piscina desbordem daqueles cujo uso é comum para tanto e não havendo prova da aquisição de tais mercadorias, não há falar em danos materiais. 4. A se tratar de típico conflito de vizinhança, mas que não desborda para ofensas, ameaças ou agressões, sem grandes consequências, não se têm danos morais compensáveis. 5. Sentença parcialmente reformada. RECURSO PARCIALMENTE PROVIDO. (Recurso Cível No 71007257017, Terceira... Turma Recursal Cível, Turmas Recursais, Relator: Fabio Vieira Heerdt, Julgado em 28/06/2018). (TJ-RS - Recurso Cível: 71007257017 RS, Relator: Fabio Vieira Heerdt, Data de Julgamento: 28/06/2018, Terceira Turma Recursal Cível, Data de Publicação: Diário da Justiça do dia 05/07/2018).
\end{abstract}

Assim, conclui-se pela ampla variedade de interpretações do Poder Judiciário brasileiro em relação à posse, à propriedade, às cláusulas gerais, etc. Supondo-se, pois, que o mesmo deve ocorrer, e de maneira mais discrepante, em outros poderes estatais - já que nem todos os agentes públicos são juristas -, a exemplo dos atos administrativos do Executivo, ocasionando um limbo jurídico.

Passa-se a analisar a jurisprudência argentina. 
Evidencia-se, primeiramente, que foram colhidos julgados da Corte Suprema de la Justicia de la Nación República Argentina. As duas primeiras dizem respeito ao preenchimento dos requisitos para a obtenção da usucapião, que, inclusive, são bem mais exigentes que os requisitos para prescrição aquisitiva brasileira:

PRESCRIPCION ADQUISITIVA - POSESION VEINTEAÑAL - CARGA DE LA PRUEBA - DOMINIO - DERECHO DE PROPIEDAD. A los fines de adquirir por prescripción el dominio de un inmueble, resulta necesario que la parte acredite fehacientemente haber entrado en la posesión de la cosa, realizando actos de naturaleza de los señalados por el art. 2373 del Código Civil y que se mantuvo en el ejercicio de esa posesión en forma continua durante los veinte años necesarios para adquirir el dominio por el medio previsto en el art. 2524 inc. $7^{\circ}$ de aquel (art. 4015 código cit.), y que el pretenso poseedor no sólo tenga la cosa bajo su poder, sino que sus actos posesorios se manifiesten de forma tal que indiquen su intención de someterla al ejercicio de un derecho de propiedad, elemento subjetivo que importa no reconocer la titularidad del dominio en otro. Malossi, Noemí Adriana c/ E.N.A. O.N.A.B.E. s/prescipción adquis. M. 1106. XLVIII. ROR; 15/07/2014; Fallos: 337:850.

USUCAPION - PRESCRIPCION ADQUISITIVA - POSESION VEINTEAÑAL CARGA DE LA PRUEBA - APRECIACION DE LA PRUEBA. Cabe revocar la sentencia que hizo lugar a la acción de prescripción adquisitiva del dominio deducida por quien declaró adquirido por usucapión un inmueble, pues no existen actos posesorios realizados a título de dueño durante el lapso de 20 años para usucapir, prueba que tiene que ser plena e indubitable, demostrativa y sin ninguna clase de duda, de que están cumplidos todos los requisitos de la ley para poder adquirir por prescripción, sumado a que las constancias de la licitación y del juicio de lanzamiento llevan a considerar que el Estado Nacional y el Organismo Nacional de Administración de Bienes, se comportaron siempre como dueños del terreno objeto del litigio sin reconocer ningún derecho a la actora sobre aquél. Malossi, Noemí Adriana c/ E.N.A. - O.N.A.B.E. s/prescipción adquis. M. 1106. XLVIII. ROR; 15/07/2014; Fallos: 337:850.

O caso subsequente, por sua vez, é bem mais antigo e trata mais especificamente da função social da propriedade, sem, contudo, defini-la. $\mathrm{O}$ que se faz é afirmar o direito à propriedade, desde que ele seja submetido às obrigações que estabelecem a lei com o fim de bem comum. Ou seja, é uma interpretação contraditória, visto que como foi exposto em tópico anterior, o bem comum é conceito aberto e "muda de acordo com a filosofia política e econômica de um governo" (SANTORO, 2011) - vide tópico 3 -, causando insegurança, portanto, a interpretação em apreço:

CONSTITUCION NACIONAL - DERECHO DE PROPIEDAD. El art. 38 de la Constitución Nacional no establece que la propiedad es una función social. La propiedad, como derecho individual, está expresamente reconocida y asegurada en su uso y disposición conforme con las leyes que, sin alterar ese derecho, reglamenten su ejercicio. La asignación de una función social a la propiedad privada sólo tiene el alcance de "someterla a las obligaciones que establezca la ley con fines 
de bien común", sin abatir los poderes de usar y disponer de ella. Caillard de O`Neill, Magdalena E. M. c/ Heguiabehere, Gerónimo. 1956. Fallos: 234:384.

Entretanto, percebe-se uma preocupação maior nas decisões argentinas em relação à restrição do direito à propriedade. Até mesmo a expressão "função social" não é de fácil identificação nas fundamentações desse Judiciário. Ademais, o compromisso com a autonomia da vontade e com as liberdades em geral, também se faz mais presente, tal qual se verifica nos seguintes julgados:

SUMARIO DE FALLO. 15 de Marzo de 2007. Id SAIJ: SUA0070553. Es regla de interpretación que todo aquel que pretenda restringir el derecho de propiedad constitucionalmente consagrado tiene la carga argumentativa de justificar la legitimidad de su decisión. Este es el efecto jurídico preciso de la calificación del contrato dentro del concepto de propiedad constitucional, ya que la regla es la libertad, mientras toda limitación es una excepción que debe ser fundada (Voto de los Dres. Ricardo Luis Lorenzetti y E. Raúl Zaffaroni).

SUMARIO DE FALLO. 27 de Diciembre de 2006. Id SAIJ: SUA0070512. El contrato y la propiedad tienen protección constitucional en el derecho argentino y toda limitación que se disponga es de interpretación restrictiva. Esta tutela comprende tanto la libertad de contratar, que es un aspecto de la autonomía personal a la que todo ciudadano tiene derecho (art. 19 Constitución Nacional), como la de configurar el contenido del contrato, que es un supuesto del derecho a ejercer una industria lícita (art. 14 Constitución Nacional) y de libertad económica dentro de las relaciones de competencia (art. 43 Constitución Nacional) (Voto del Dr. Ricardo Luis Lorenzetti)

Finaliza-se com a jurisprudência que trata a relação precária de poder em relação à coisa como detenção, não como posse. Seria essa classificação correspondente à posse precária constante no Código Civil, que, na verdade, não poderia estar sendo chamada assim conforme vários doutrinadores. Ainda merece destaque a decisão, já que fica clarividente a extensão dos efeitos da decisão restitutiva da coisa "contra todos os que ocupem o imóvel", o que pode envolver, inclusive, pessoas que ocuparam por outras vias que não o abuso de confiança.

SUMARIO DE FALLO. 19 de Diciembre de 1995; Id SAIJ: SUD0010356. La acción de desalojo puede ser dirigida contra todo tenedor a título precario, intruso o cualquier ocupante, cuya obligación de restituir sea exigible, haya o no contrato (art. 680 del Código Procesal; esta Cámara, Sala II, Causas 9473/93 del 22.11.94). Y como la sentencia se hará efectiva contra todos los que ocupen el inmueble, aún cuando no hayan sido mencionados en la diligencia de notificación o no se hayan presentado en el juicio (art. 687 del Cód. cit.), no resulta lógico deducir que quedan excluidos los menores. Ello es así, no solo porque no lo menciona en forma específica la norma en cuestión ni ninguna otra de la Ley de rito, sino porque sería 
inconcebible que los propietarios de inmuebles ocupados o cualquiera que posea un interés legítimo para reclamar el desalojo, deban otorgar a los menores la protección y el amparo que incumbe prestar a quienes ostentan la patria potestad. Conclusión que se confirma si se pondera que se trata de una "tenencia precaria", de modo que la obligación de restituir surge limpiamente de la propia condición de los ocupantes e involucra a todos ellos, quienes solo habitan el inmueble por tolerancia de quien aquí demanda (cfr. esta Cámara, Sala II, Causa 9470/93 del 1.12.94).

Assim, foi possível perceber que a atividade interpretativa argentina também é destoante, uma vez que se observaram várias fundamentações em sentidos distintos. Entretanto, também se constatou que, ainda assim, as decisões argentinas tendem a ser mais favoráveis ao liberalismo e aos direitos dele decorrentes, tal qual a propriedade privada. Acredita-se, pois, que a menor recorrência de situações conflitivas envolvendo posses e propriedades na realidade argentina em relação à brasileira - embora sejam países com quantidades populacionais diferentes -, possa estar diretamente relacionada com o modo interpretativo do seu Judiciário.

\section{CONSIDERAÇÕES FINAIS}

Com o presente estudo foi possível perceber a grande influência dos fatos históricos ocorridos no século passado para o direito. Dois modos de organização social antagônicos afloraram e prevaleceu o modelo capitalista, em que a propriedade privada ganha posição central, embora desde muito tempo atrás a relação de poder entre o ser humano e as coisas ao seu redor já existisse, sendo algo que perfaz sua essência, motivo pelo qual o liberalismo defende a existência da propriedade privada como direito natural.

Desse modo, com a emergências das codificações, e, posteriormente, com o advento das constituições sociais democráticas, em que ideias de superação do individualismo e ascensão do coletivo, do social e dos direitos humanos estavam presentes, a propriedade passou a sofrer restrições, a exemplo da necessidade de observância da sua função social.

Acontece que pela mobilidade do termo, a interpretação caso a caso fica a mercê de subjetivismos e, consequentemente, da insegurança jurídica. Destacou-se, além da função social, a possibilidade da convalidação da posse e consequente aquisição de propriedade por prescrição em ambos os países, concluindo pelas diferentes tratativas dadas pelos códigos desses lugares, especificamente no bojo dos direitos reais, sendo o argentino mais liberal que o brasileiro, este com forte marca social. Em países como os em apreço, os conflitos 
envolvendo a posse e/ou propriedade acontecem diuturnamente, tal qual em outras nações da América Latina. Entretanto, ainda assim a recorrência hostil no Brasil é significativamente superior e conta com casos mais violentos.

Tendo isso em vista, o pensamento liberal poderia contribuir, considerando sua grande reivindicação pela não agressão e respeitos às liberdades, mormente o vislumbre de decisões jurisprudenciais mais protetivas à propriedade na Argentina, onde o problema é menor que no Brasil. Em que pese esse fato, merece destaque que, surpreendentemente, constatou-se que a interpretação brasileira de cunho mais social tem sido em alguma medida mais mitigada que o esperado, abrindo a possibilidade investigativa ao modo com tem lidado com os casos conflitivos o Poder Executivo.

\section{REFERÊNCIAS BIBLIOGRÁFICAS}

ABREU, Luciana. La configuración de la propiedad comunitária indigena em el Nuevo Código Civil y Comercial. Reflexiones desde la dimensión ambiental y desde los derechos bioculturales. p. 141 - 165. IN: CABANILLAS, Renato Rabbi-Balbi. Los derechos de la persona en el nuevo Código Civil y Comercial. Aproximación a algunos aspectos novedosos. 1. ed. Ciudad Autónoma de Buenos Aires: La Ley, 2017.

ARGENTINA. CODIGO CIVIL Y COMERCIAL DE LA NACION. Ley 26.994.

Disponível em: <http://servicios.infoleg.gob.ar/infolegInternet/anexos/235000-

239999/235975/norma.htm\#25> Acesso em: 24. fev. 2019.

ARGENTINA. Constitución de La Nación Argentina. 22 de agosto de 1994. Disponível em: < https://www.constitution.org/cons/argentin.htm>. Acesso em: 23. fev. 2019.

ARGENTINA. Ministerio de Justicia y Derechos Humanos - Jurisprudencia. Disponível em: <www.saij.gob.ar>. Acesso em: 24. fev. 2019.

BEVILAQUA, Clovis. Código Civil dos Estados Unidos do Brasil Comentado. vol. III. 11. ed. Rio de Janeiro: Francisco Alves, 1958.

BRASIL. Código Civil. 16. ed. São Paulo: Rideel, 2010.

BRASIL. Constituição da República Federativa do Brasil. Promulgação em

05/10/1988.Disponível em: <http://portal.itapetininga.sp.gov.br/media/doc/contitfederal.pdf>. Acesso em 04 de maio de 2018.

BRASIL. Jusbrasil - Jurisprudência. Disponível em:

<https://www.jusbrasil.com.br/jurisprudencia/?ref=navbar>. Acesso em: 25. fev. 2019

Revista Brasileira de Direito Civil em Perspectiva | e-ISSN: 2526-0243 | Belém | v. 5 | n. 2 |

p. 42 - 62 | Jul/Dez. 2019. 
CONVENÇÃO AMERICANA DE DIREITOS HUMANOS. Pacto de São José da Costa

Rica. Disponível em: <

http://www.pge.sp.gov.br/centrodeestudos/bibliotecavirtual/instrumentos/sanjose.htm>.

Acesso em: 24. fev. 2019

DINIZ, Maria Helena. Curso de direito civil brasileiro. v.1: teoria geral do direito civil. 28. ed. São Paulo: Saraiva, 2011.

GLOBAL WITNESS LIMITED. Defender la tierra. Londres: Global Witness, 2017. (ISBN 978-1-911606-02-40).

GONÇALVES, Carlos Roberto. Direito civil brasileiro, vol. 5: direito das coisas. 12. ed. São Paulo: Saraiva, 2017.

HOPPE, Hans-Hermann. A ética e a economia da propriedade privada. Disponível em: < https://www.mises.org.br/Article.aspx?id=965>. Acesso em: 24 fev. 2019.

KIPER, Claudio. Manual de Derechos Reales. 1. ed. rev. Santa Fé: Rubinzal-Culzoni, 2016.

MISES, Ludwig von. As seis lições; trad. de Maria Luiza X. de A. Borges. 9. ed. rev. São Paulo: LVM, 2018. 184 p.

QUINTELLA, Felipe. Repensando o Direito Civil Brasileiro (5): A convalidação da posse precária. 2016. Disponível em: <http://genjuridico.com.br/2016/10/21/repensando-o-direitocivil-brasileiro-5-a-convalidacao-da-posse-precaria/>. Acesso em: 23 fev. 2019.

ROTHBARD, Murray N. A Ética da Liberdade. São Paulo: Instituto Ludwig von Mises Brasil, 2010.

SANTORO, Bernardo. Por que não existe propriedade privada de imóveis no Brasil.

Disponível em: <https://www.mises.org.br/Article.aspx?id=965>. Acesso em: 24 fev. 2019.

TARTUCE, Flávio. Direito Civil. v. 4: Direito das Coisas. 5. ed. rev., atual. e ampl. Rio de Janeiro: Forense, 2014. 